\section{BMJ Paediatrics Open}

\title{
Birth prevalence of encephalocele in Africa: a systematic review and meta- analysis
}

\author{
Mohammed Oumer (D) , ${ }^{1}$ Alemnew Demissie Kassahun ${ }^{2}$
}

To cite: Oumer M, Demissie Kassahun A. Birth prevalence of encephalocele in Africa: a systematic review and meta-analysis. BMJ Paediatrics Open 2021;5:e001117. doi:10.1136/ bmjpo-2021-001117

- Additional supplemental material is published online only. To view, please visit the journal online (http://dx.doi.org/ 10.1136/bmjpo-2021-001117).

Received 14 April 2021 Accepted 13 September 2021

Check for updates

\section{(c) Author(s) (or their} employer(s)) 2021. Re-use permitted under CC BY-NC. No commercial re-use. See rights and permissions. Published by BMJ.

${ }^{1}$ Department of Human Anatomy, School of Medicine, College of Medicine and Health Sciences, University of Gondar, Gondar, Amhara, Ethiopia

${ }^{2}$ Department of Ophthalmology, School of Medicine, College of Medicine and Health Sciences, University of Gondar, Gondar, Amhara, Ethiopia

Correspondence to Mohammed Oumer; Mohammed.0umer@uog.edu.et

\section{ABSTRACT}

Objective To identify the birth prevalence of encephalocele in Africa, 2020.

Methods We carried out a systematic search of the following databases (PubMed/Medline, PubMed Central, Joanna Briggs Institute (JBI) Library, Cochrane Library, Web of Science, Google Scholar, Science Direct, African Journals Online and Embase), using search terms (prevalence, encephalocele, "neural tube defects", "cranium bifidum", "congenital malformations", "congenital defects", "structural birth defects", "structural abnormalities", newborns/neonates/ "live births"/ "stillbirths" and their MeSH Terms) up to 16 July 2021. The JBI quality appraisal checklist was used to assess the quality of studies when they were abstracted using a standardised data extraction template. The $\mathrm{I}^{2}$ statistic and Cochrane $\mathrm{Q}$ test were used to examine heterogeneity across studies statistically. The prevalence of encephalocele was estimated using a random-effect meta-analysis model. Subgroup, sensitivity, meta-regression and time trend analysis were carried out. The publication bias was checked using Egger and Begg's tests.

Results Twenty-seven relevant studies were identified and provided a total of 5107109 births. In this systematic review and meta-analysis, the pooled birth prevalence of encephalocele in Africa was $0.02 \%$ (or 2 per 10000 births) ( $95 \% \mathrm{Cl} 0.02 \%$ to $0.03 \%$ ). The overall prevalence of birth encephalocele using the median from studies was $0.02 \%$ (IQR $=0.01 \%-0.04 \%)$. Higher prevalence of encephalocele was detected in Nigeria $0.06 \%$ (95\% $\mathrm{Cl} 0.04 \%$ to $0.08 \%)$, Sudan $0.04 \%$ ( $95 \% \mathrm{Cl} 0.03 \%$ to $0.05 \%$ ), Egypt $0.04 \%$ ( $95 \% \mathrm{Cl} 0.04 \%$ to $0.05 \%)$, DR of Congo $0.02 \%(95 \% \mathrm{Cl}$ $0.02 \%$ to $0.03 \%)$, Ethiopia $0.02 \%(95 \% \mathrm{Cl}-0.004 \%$ to $0.05 \%$ ) and Tanzania $0.02 \%(95 \% \mathrm{Cl} 0.002 \%$ to $0.04 \%)$. The prevalence of encephalocele per live birth was $0.03 \%$ and both live birth and stillbirth was $0.03 \%$.

Conclusions This review indicates a high prevalence of encephalocele, but studies were limited suggesting the need for additional research.

PROSPERO registration number CRD42021242161.

\section{INTRODUCTION}

Encephalocele is a birth abnormality associated with skull deformities defined by a partial absence of bone fusion, allowing a portion of the brain to protrude through a gap. ${ }^{1-3}$ It is a form of neural tube birth abnormality that affects the brain..$^{2-6}$ The neural tube is a tiny canal that folds and closes to form the fetus's

\section{What is known about the subject?}

- Encephalocele is a birth abnormality associated with skull deformities defined by a partial absence of bone fusion that a portion of the brain protrudes.

- It is one of the leading causes of death and disability in newborns.

\section{What this study adds?}

Although there are fragmented studies estimating the prevalence of encephalocele, there was no systematic review and meta-analysis on isolated encephalocele presenting this evidence.

- This review highlights the birth prevalence of encephalocele in African countries, providing crucial evidence for policymakers, clinicians and the concerned bodies.

- This systematic review and meta-analysis will contribute to assist the prevention and control programmes.

brain and spinal cord during the third and fourth weeks of gestation. ${ }^{146}$

An opening will appear anywhere along the centre of the skull from the nose to the back of the neck following the defect, but most commonly at the back of the head, the top of the head or between the forehead and the nose. ${ }^{13}$ Encephalocele is a sac-like protrusion of the brain and meninges through a hole in the skull (usually affecting the occipital area, the back of the skull). ${ }^{26}$ The protruding region of the brain is frequently covered by skin or a thin membrane, giving the abnormality the appearance of a tiny sac. ${ }^{5}$ Its herniation process manifests as a pedunculated (with a stalk-like base) or sessile (with no stalk) cystic lesion. ${ }^{2}$ Only the meninges protrude through the bone opening in the sac, causing cranial meningocele; however, the herniated sac contains brain tissue and meninges, causing encephalocele or meningoencephalocele. Hydroencephalocele is a deformity that occurs when a herniated 
sac contains a ventricle. Encephalomyelocele is a type of encephalocele that contains tissue from the brain and spinal cord. ${ }^{1-9}$ Anatomically, encephalocele can be classified into sincipital (nasoorbital, frontoethmoidal, nasofrontal, interfrontal, nasoethmoidal, craniofacial cleft), basal (sphenoorbital, sphenomaxillary, intranasal, spenopharyngeal), convexity (sagittal, occipital, occipitocervical, parietal) and atretic. ${ }^{810}{ }^{11}$ Evidence suggests that an encephalocele is a form of postneurulation defect distinct from closure-related neural tube defects. ${ }^{8}{ }^{12}$

The incidence of encephalocele varies by race and geographical region, ranging from 0.8 to 4 per 10000 births. ${ }^{7811}$ According to the Centers for Disease Control and Prevention, encephalocele affects 1 out of every 10000 babies born in the USA each year. ${ }^{1}$

The majority of encephaloceles are massive, serious birth abnormalities that are detected before delivery. Some encephaloceles, however, are small and go undetected in extremely uncommon circumstances. Although the specific aetiology of encephalocele is uncertain, scientists believe it is caused by a combination of causes. ${ }^{1-3}$

The symptoms of an encephalocele vary from person to person, based on a variety of characteristics such as the size, location, and amount and kind of brain tissue protruding from the skull. The placement of the encephalocele is crucial because anterior (which usually does not contain brain tissue and has a better prognosis) and posterior (often associated with neurological problems) encephaloceles have different clinical consequences/ implications for therapy and prognosis. Surgical management is usually required to return the protruding section of the brain and meninges to the skull and shut the incision/opening. However, encephalocele-related neurological issues will persist, and long-term care may be required depending on the child's condition. ${ }^{12}$

Encephalocele is the leading cause of death and disability in newborns, ${ }^{6} 101314$ despite the fact that it can be reduced by various preventive and control strategies. Preventive strategies such as folic acid supplementation or fortification of staple foods can help to reduce it. $^{3-6} 1314$ In order to make decisions and plan preventative services, it is essential to provide information to responsible bodies concerning the burden of encephalocele in Africa. The government, policy-makers, health professionals, researchers, medical students, communities and non-governmental organisations will benefit from this review, which will help to reduce the burden of the encephalocele and allow for more study. Moreover, little is known about the magnitude of encephalocele in Africa as a whole. Thus, the present systematic review and meta-analysis aimed to identify the pooled birth prevalence of encephalocele in Africa, 2020

\section{METHODS}

Reporting of the findings and review registration

Preferred Reporting Items for Systematic Reviews and Meta-Analyses statements were used to report the current systematic review and meta-analysis ${ }^{15}$ (online supplemental file 1). The review protocol has been registered in PROSPERO with the registration ID of CRD42021242161.

\section{Search strategies}

PubMed/Medline, PubMed Central, Cochrane Library, Joanna Briggs Institute (JBI) Library, Science Direct, Web of Science, African Journals Online, WHO, UCSF and Embase databases were systematically searched for relevant studies (reference lists of identified articles were also navigated) up to 16 July 2021. The primary search was conducted in an advanced PubMed database (using search terms prevalence, encephalocele, "neural tube defects", "cranium bifidum", "congenital malformations", "congenital defects", "structural birth defects", "structural abnormalities", newborns/neonates/"live births"/"stillbirths" and their MeSH Terms). The core search terms and phrases were considered interchangeably in different databases. Moreover, grey literature was retrieved using Google and Google Scholar searches. The full search strategy is being shown online (online supplemental file 2).

\section{Eligibility criteria}

\section{Inclusion criteria}

Published and unpublished full-text studies in any period and study designs (a cross-sectional, prospective cohort that included original data) that report the birth prevalence of encephalocele in Africa were included in this review.

\section{Exclusion criteria}

Case reports, conferences, editorials, anonymous reports and research with limited access (after two emails to the corresponding author) were excluded from the review. Moreover, a study was excluded if the total number of cases and births included in the study were not indicated explicitly.

\section{Review outcomes}

The outcome of the current review was the pooled birth prevalence of encephalocele in Africa. Birth prevalence of encephalocele is defined as the number of encephalocele cases of live births and/or stillbirths at birth (numerator) from the total number of births (live births and/or stillbirths) during the study period (denominator).

\section{Quality assessment}

The JBI quality appraisal checklist was used to evaluate the quality of each study. ${ }^{16}$ The JBI critical appraisal checklist (which has nine items) was adapted for the studies reporting the prevalence data (online supplemental file 3). Using the framework, two reviewers (MO and $\mathrm{AD})$ independently evaluated the quality of each study. During the evaluation of quality, disagreements between reviewers were resolved by using the average score of the two reviewers. In the end, if the study received five 
or more points on all quality assessment items, it was deemed low risk. ${ }^{17}$

\section{Study selection and data abstraction}

After retrieving all of the studies from the databases, they were loaded into the reference manager, an Endnote V.7 software program, to eliminate duplicates. The reviewers then screened the research for inclusion based on the title and abstract. All necessary data were extracted independently by two reviewers ( $\mathrm{MO}$ and $\mathrm{AD}$ ) using a defined data extraction template after thoroughly reading fulltext studies and including the eligible studies. The main author, sample size, study nation, study duration, study design, study location, publication year, prevalence period, folic acid fortification policy, birth status, birth outcome and birth prevalence of encephalocele were all included in this template.

\section{Meta-analysis}

For further analysis, the data were extracted in Microsoft Excel and exported to STATA V.14 Statistical Software. For each study, the prevalence was estimated per hundred births to preserve uniformity.

The Cochrane $\mathrm{Q}$ test and the $\mathrm{I}^{2}$ statistic were used to examine statistically the heterogeneity between studies and a forest plot was used to visualise heterogeneity. ${ }^{18}$ This revealed considerable heterogeneity among studies $(\mathrm{p}<0.001)$. Therefore, to determine the pooled prevalence of encephalocele, a random-effect metaanalysis approach was applied. ${ }^{19}{ }^{20}$ Subgroup analysis was performed based on selected variables (the study country, study design, birth outcome, folic acid fortification status, epidemiological design and status of births). A sensitivity analysis was done to see the influence of a single study on the overall estimate of meta-analysis. Meta-regression analysis was accounted for to identify the source of heterogeneity. A time-trend analysis was conducted as well.

\section{Assessment of publication bias}

Graphically, Egger's plot was used to visualise the publication bias. Objectively, Egger's regression test and Begg's test statistics were used to detecting publication bias. ${ }^{21} 22$ As a result, publication bias was defined as a $\mathrm{p} \leq$ of 0.05 .

\section{Patient and public involvement}

'No patient involved.'

\section{RESULTS}

\section{Study selection}

A total of 5422 articles were initially retrieved on the prevalence of encephalocele through PubMed, Google Scholar and others from Cochrane, JBI Library, WHO, Medline, UCSF, African Journal Online, Science Direct and Embase. Of these, 1536 were excluded due to duplicated articles. From the remaining 3886 studies, 3660 studies were excluded after reviewing the titles and abstracts because they were found non-relevant for this review. Full texts of the remaining 226 studies

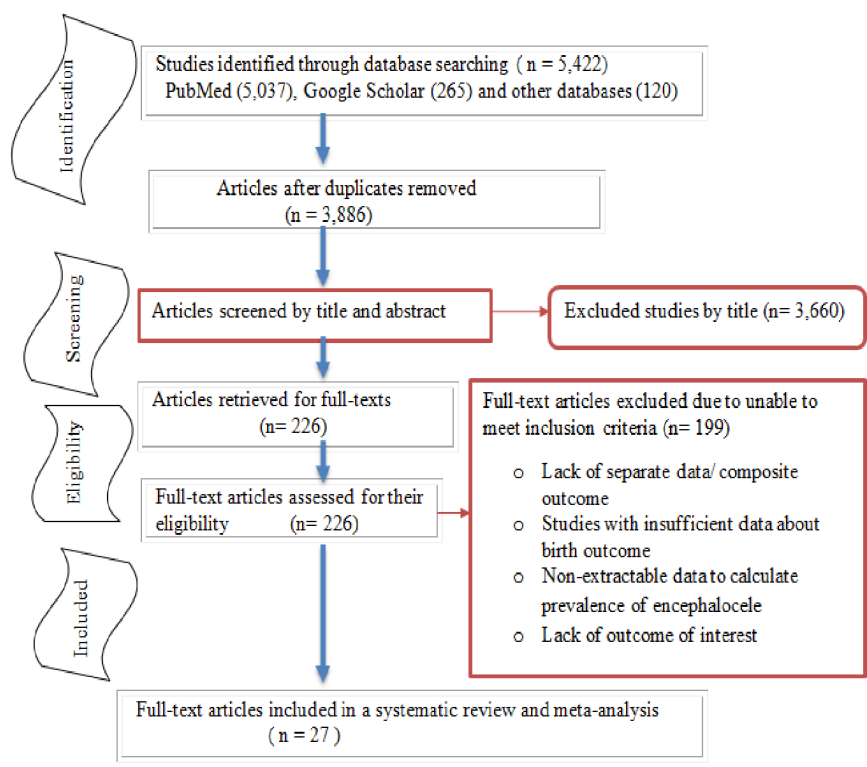

Figure 1 Study selection flow diagram; a figure adapted from the PRISMA group statement for this review. PRISMA, Preferred Reporting Items for Systematic Reviews and MetaAnalyses.

were screened. This systematic review and meta-analysis comprised 27 studies that met the inclusion criteria ${ }^{23-49}$ (figure 1).

\section{Characteristics of the original studies}

The included studies were either cross-sectional $(n=4)$, retrospective $(n=14)$ or prospective studies $(n=9) \cdot{ }^{23-49}$ Of all studies, eight were conducted in Nigeria, ${ }^{23-30}$ three in South Africa, ${ }^{1-33}$ two in Ethiopia, ${ }^{4041}$ two in Tanzania, ${ }^{3435}$ two in Kenya ${ }^{3637}$ and two in Sudan. ${ }^{3839}$ Studies conducted in Morocco, Tunisia, Algeria, the Democratic Republic (DR) of Congo, Egypt, Cameron, Ghana and Libya were also identified. ${ }^{42-49}$ All studies included in this review were facility-based studies, published in the year between 1992 and 2020. ${ }^{23-49}$ South Africa (started fortification in 2003), Nigeria (in 2002), Tanzania (in 2011) and Kenya (in 2012) have mandatory folic acid fortification with Wheat Flour and Maize Flour. Morocco (in 2006), Cameron (in 2011) and Ghana (in 2006) have mandatory folic acid fortification with Wheat Flour. Ethiopia and Sudan have a voluntary folic acid fortification policy with Wheat Flour at this time. Based on birth status, four studies mentioned the inclusion of twin birth and multiple births in addition to singleton births ${ }^{29} 364043$ while all other studies not mentioned their birth status. Generally, 27 studies reported a total of 5107109 births, ranged from 1456 to 3803889 births $^{2746}$ (table 1).

\section{Quality of the studies}

Using JBI quality appraisal criteria, all included studies were evaluated for their quality. Each study was evaluated using the evaluation checklist for prevalence studies, which consists of nine questions/items with yes, no, unclear or not applicable responses. The quality assessment grading for all items was based on the JBI 


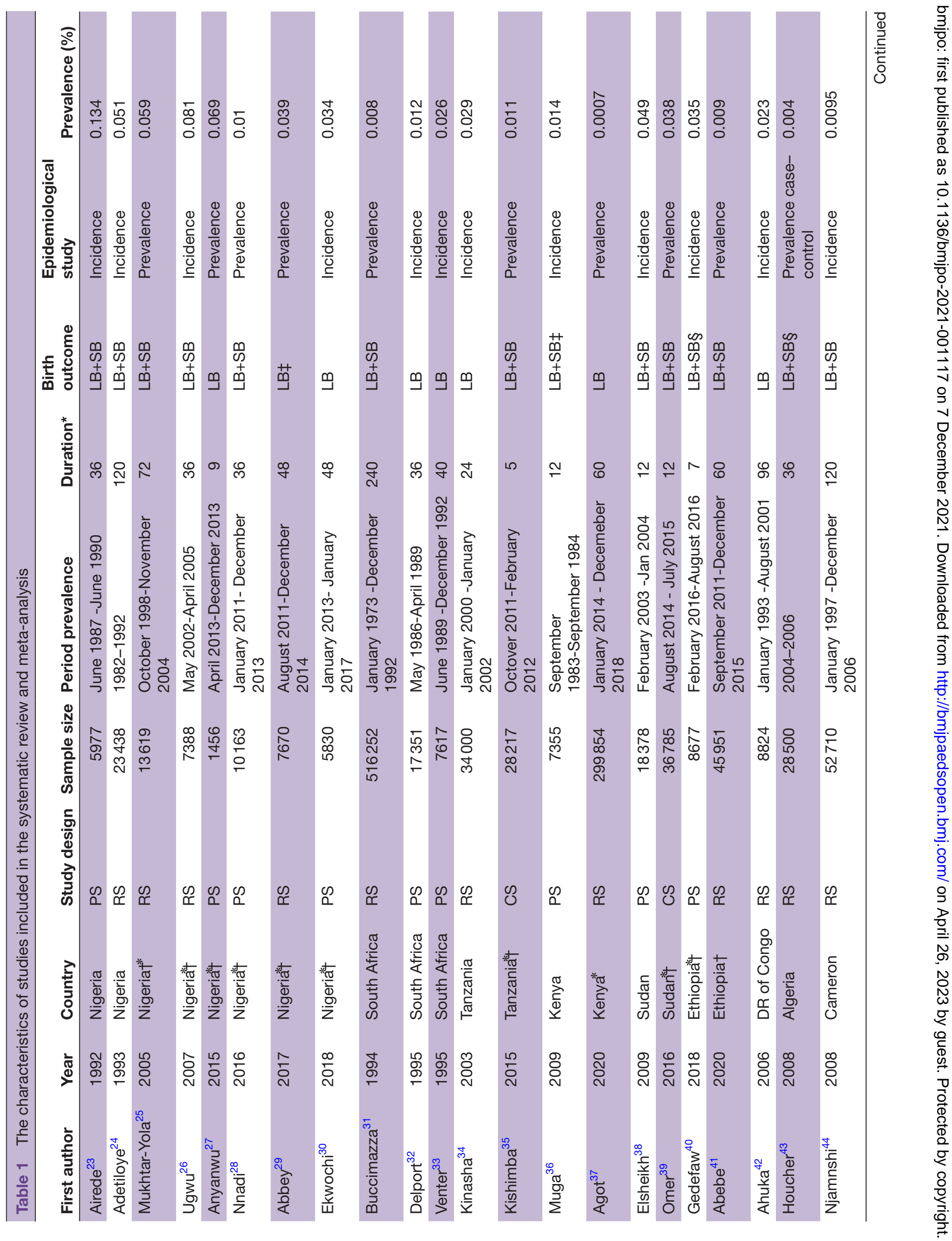




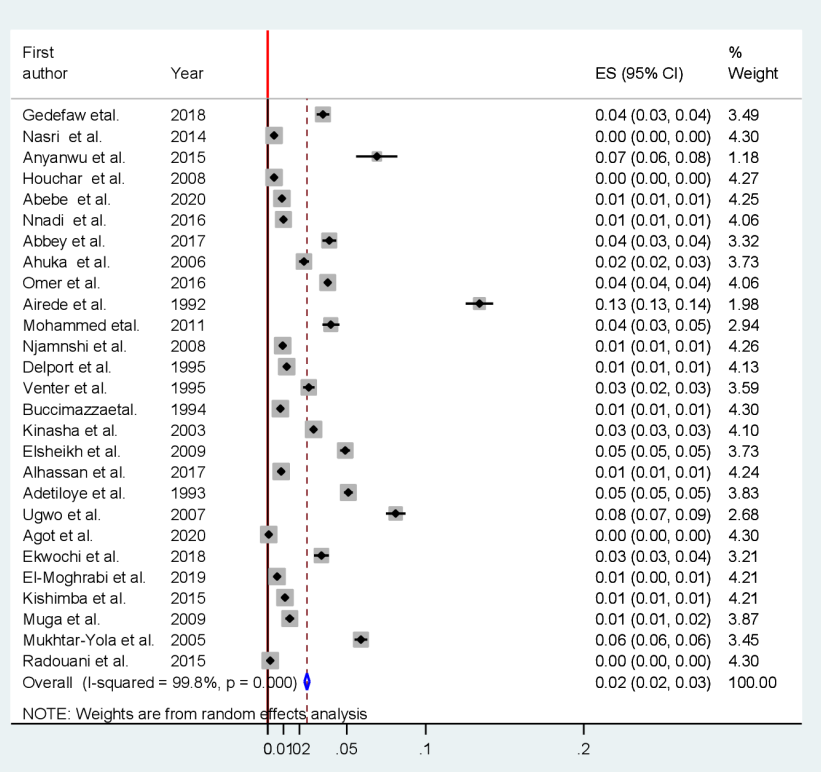

Figure 2 Forest plot showing the pooled prevalence of encephalocele in Africa. ES, Effect Size

descriptions for each item. As a result, the studies' quality scores ranged from four to nine. Therefore, except for one study that received a four, none of the studies had a significant risk of being of poor quality ${ }^{23-49}$ (online supplemental file 4).

\section{Meta-analysis}

Prevalence of encephalocele

In the present meta-analysis, the pooled birth prevalence of encephalocele was $0.02 \%$ (or 2 per 10000 births) $(95 \%$ CI $0.02 \%$ to $0.03 \%$ ). A Forest plot showed that there was statistically significant heterogeneity across the studies. Therefore, the random-effect meta-analysis model was applied to pool the overall prevalence of the studies (figure 2). Considering all included studies, the median value of birth encephalocele was $0.02 \%$ and the IQR was between $0.01 \%$ and $0.04 \%$. The minimum and maximum values of birth encephalocele were $0.0007 \%$ and $0.134 \%$, respectively (online supplemental file 5).

\section{Subgroup analysis}

Subgroup analysis based on the study country, study design, birth outcome, folic acid fortification status, epidemiological design and status of births was carried out to see the variation of the prevalence across the studies.

Subgroup analysis based on the study country was performed to see the pooled prevalence of each country in Africa. High pooled prevalence of encephalocele was detected in Nigeria $0.06 \%$ (95\% CI $0.04 \%$ to $0.08 \%$ ), Sudan $0.04 \%$ (95\% CI $0.03 \%$ to $0.05 \%$ ), Egypt $0.04 \%$ ( $95 \%$ CI $0.04 \%$ to $0.05 \%$ ), DR of Congo $0.02 \%$ (95\% CI $0.02 \%$ to $0.03 \%$ ), Ethiopia $0.02 \%$ (95\% CI $-0.004 \%$ to $0.05 \%$ ) and Tanzania $0.02 \%$ (95\% CI $0.002 \%$ to $0.04 \%$ ) (table 2). In the present review, statistically significant 
Table 2 The pooled prevalence of encephalocele among African countries

\begin{tabular}{ll}
\hline Country & Prevalence in \% $(95 \%$ Cl) \\
\hline Morocco & $0.002(0.001$ to 0.002$)$ \\
\hline Tunisia & $0.004(0.004$ to 0.004$)$ \\
\hline Algeria & $0.004(0.003$ to 0.005$)$ \\
\hline Libya & $0.006(0.005$ to 0.007$)$ \\
\hline Kenya & $0.007(-0.006$ to 0.020$)$ \\
\hline Cameron & $0.009(0.009$ to 0.010$)$ \\
\hline Ghana & $0.009(0.008$ to 0.009$)$ \\
\hline South Africa & $0.015(0.008$ to 0.022$)$ \\
\hline Tanzania & $0.020(0.002$ to 0.038$)$ \\
\hline Ethiopia & $0.022(-0.004$ to 0.047$)$ \\
\hline DR of Congo & $0.023(0.020$ to 0.026$)$ \\
\hline Egypt & $0.040(0.035$ to 0.045$)$ \\
\hline Sudan & $0.043(0.033$ to 0.054$)$ \\
\hline Nigeria & $0.059(0.038$ to 0.081$)$ \\
\hline D+L pooled ES & $0.025(0.023$ to 0.027$)$ \\
\hline
\end{tabular}

D+L, Der Simonian and Laird; DR, Democratic Republic; ES, Effect Size.

heterogeneity between countries was detected $(\mathrm{p}=0.001$, $\left.\mathrm{I}^{2}=97.1 \%-99.8 \%\right)$. Therefore, the Der Simonian and Laird's $(\mathrm{D}+\mathrm{L})$ pooled prevalence method was considered because it is more conservative than the inverse variance method. The difference between countries was significant $(\mathrm{p}<0.001)$.

Subgroup analysis based on study design, using the $\mathrm{D}+\mathrm{L}$ method $\left(\mathrm{p}<0.001, \mathrm{I}^{2}=99.4 \%-99.9 \%\right)$, the prevalence of encephalocele for retrospective studies was $0.02 \%$ and for prospective studies was $0.04 \%$ (figure 3 ).

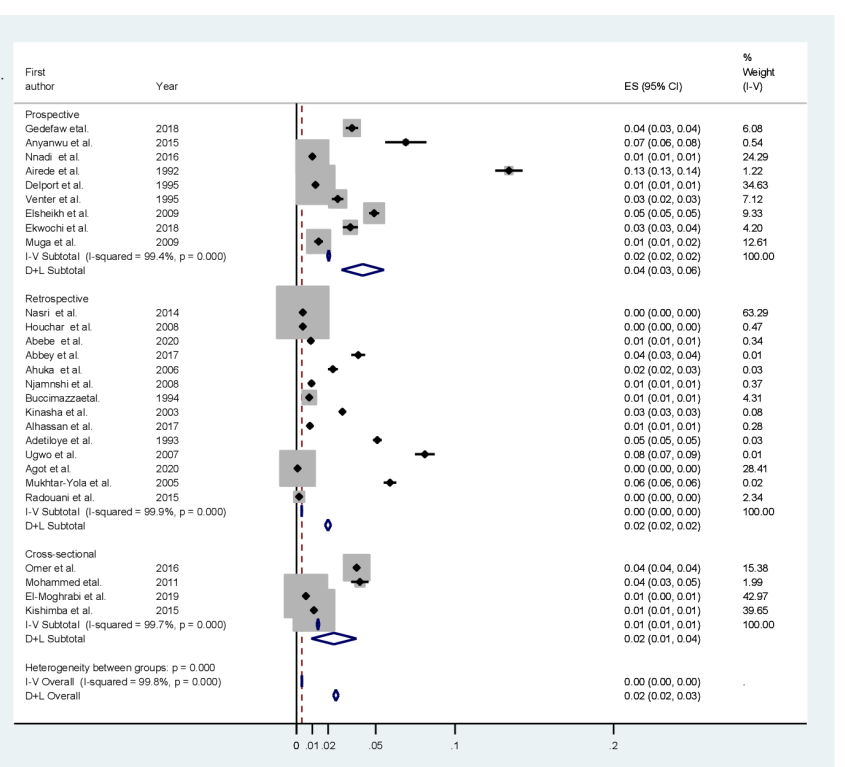

Figure 3 Subgroup analysis based on study design in Africa. ES, Effect Size

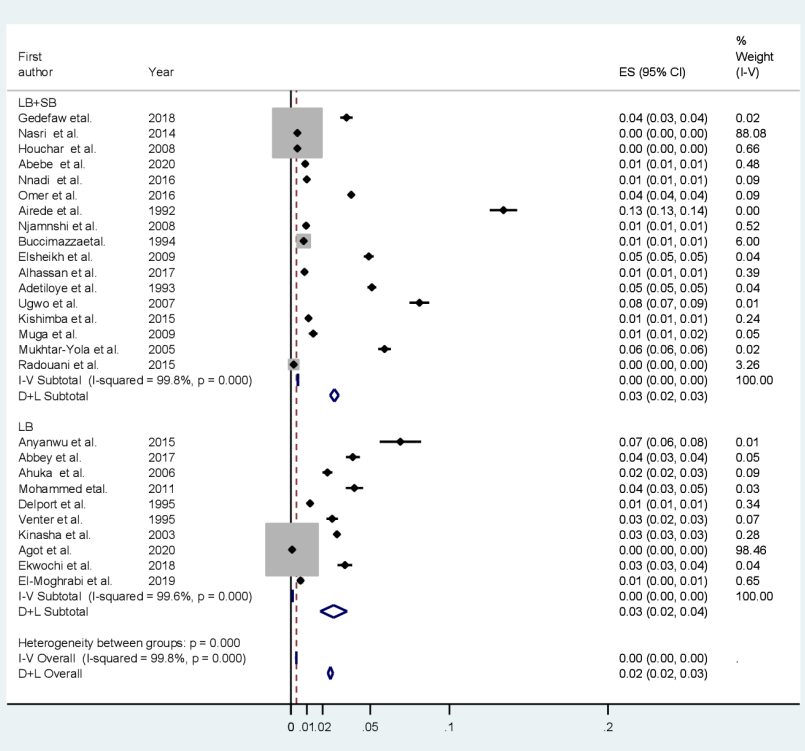

Figure 4 Subgroup analysis based on birth outcome in Africa. ES, Effect Size; LB, Live Births; SB, Stillbirths

Subgroup analysis based on birth outcome was done to see the burden in live births only (LB) and both live births and stillbirths $(\mathrm{LB}+\mathrm{SB})$. The pooled prevalence of encephalocele per live birth was $0.03 \%$ (95\% CI $0.02 \%$ to $0.04 \%$ ) and both live birth and stillbirth was $0.03 \%$ (95\% CI $0.02 \%$ to $0.03 \%$ ) (figure 4 ).

Subgroup analysis based on folic acid fortification policy was considered $\left(\mathrm{p}<0.001, \mathrm{I}^{2}=99.7 \%\right)$ and the prevalence of encephalocele for countries that had a mandatory and/or voluntary folic acid fortification was $0.03 \%$ (95\% CI $0.02 \%$ to $0.03 \%$ ), and for countries that had no either a mandatory or voluntary fortification was $0.03 \%$ (95\% CI $0.02 \%$ to $0.03 \%)$.

The prevalence of encephalocele for incidence studies was $0.04 \%$ (95\% CI $0.03 \%$ to $0.05 \%$ ), for prevalence studies was $0.02 \%$ (95\% CI $0.02 \%$ to $0.02 \%$ ) and for prevalence case-control studies was $0.004 \%$ (95\% CI $0.003 \%$ to $0.005 \%$ ).

The prevalence of encephalocele for singleton births was $0.03 \%$ ( $95 \%$ CI $0.02 \%$ to $0.03 \%)$, for singleton and twin births was $0.02 \%$ (95\% CI $-0.01 \%$ to $0.05 \%)$ and for singleton, twin and multiple births was $0.03 \%$ (95\% CI $0.002 \%$ to $0.05 \%$ ).

\section{Meta-regression analysis}

In the present systematic review and meta-analysis, sample size $(p=0.44)$, year of publication $(p=0.34)$, duration of the study in months $(\mathrm{p}=0.20)$, study country $(\mathrm{p}=0.02)$, study design $(\mathrm{p}=0.56)$, birth outcome $(\mathrm{p}=0.55)$, epidemiological design $(\mathrm{p}=0.37)$, folic acid fortification $(p=0.91)$, and the JBI quality score $(p=0.06)$ were analysed for the source of heterogeneity. The only study country was significant for the source of heterogeneity. 


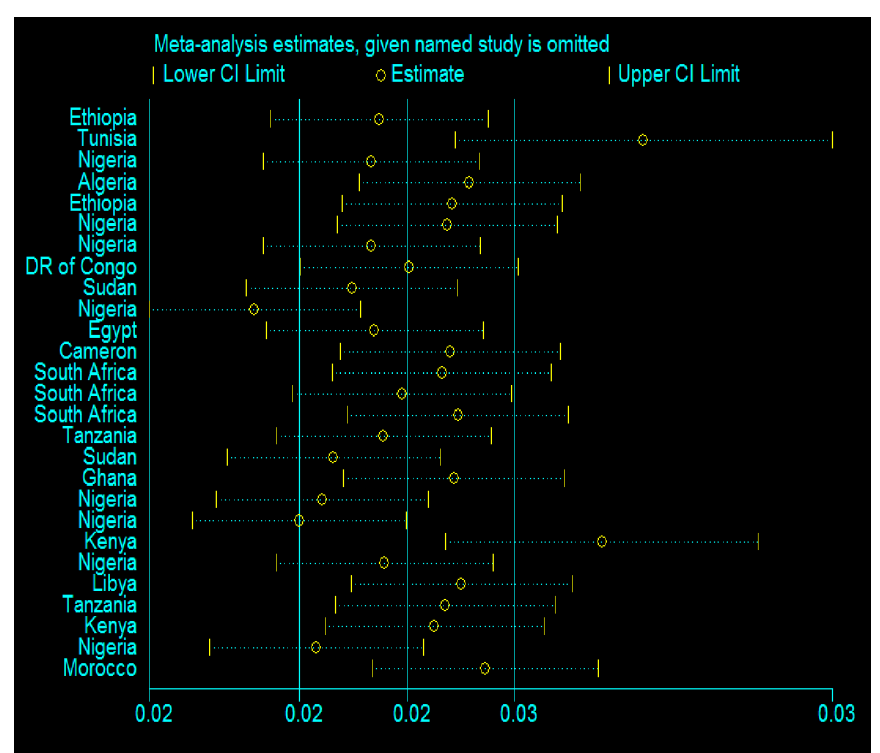

Figure 5 Sensitivity analysis to see the influence of each individual study in Africa.

\section{Sensitivity analysis}

In this review, no study was found that has a special influence over others on the overall estimation of metaanalysis (figure 5). Essentially, all studies have uniform confidence intervals. Sensitivity analysis does not help to explain heterogeneity because the heterogeneity between studies was not significantly reduced $\left(\mathrm{p}<0.001, \mathrm{I}^{2}=99.7 \%-\right.$ $99.8 \%$ ), after doing the analysis with a few studies. We performed also leave-one-out analyses; the heterogeneity among studies was not significantly reduced.

We used sensitivity analysis to examine the impact of low-quality studies on total estimates by reducing the number of studies included in a meta-analysis. We found the meta-analysis estimates by including only high-quality studies with a score greater than or equal to five. As a result, we got a similar output with the previous finding and, the pooled estimate was $0.02 \%(95 \%$ CI $0.02 \%$ to $0.03 \%$ ).

\section{Time-trend analysis}

The time-trend analysis showed the relationship between the prevalence of encephalocele and publication year. In this trend in Africa, the highest peak of encephalocele in prevalence was observed in 1992, 2007, 2014-2015 and 2005 (figure 6).

\section{Publication bias}

Publication bias was estimated using the Egger's regression tests (B-coefficient of bias: 17; $\mathrm{p}=0.001$ ). Egger's plot supported its results (figure 7 ).

\section{DISCUSSION}

Encephalocele is a central nervous system abnormality that occurs at birth. The hidden burden of encephalocele was high in Africa. Data is lacking on the true burden of this condition, leading to neglect in the treatment and

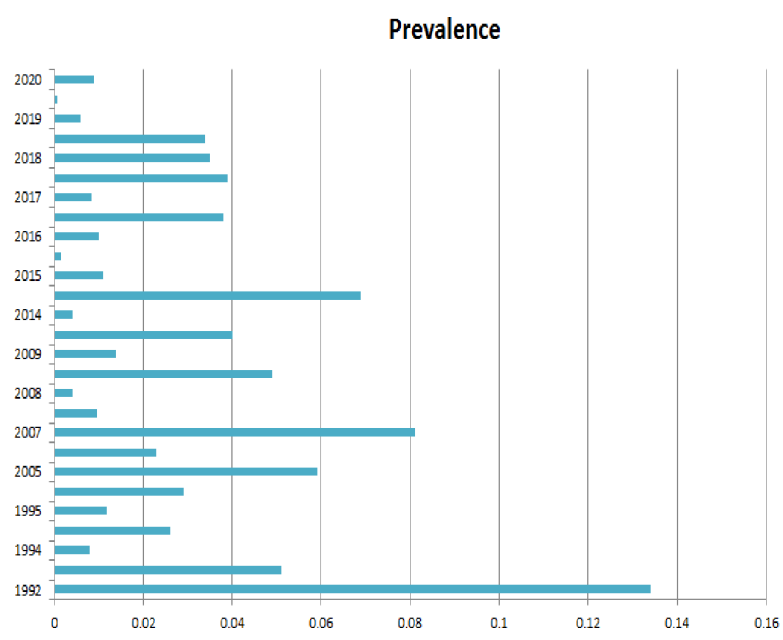

Figure 6 Time trend analysis of the prevalence of encephalocele in relation to publication year in Africa.

prevention by health systems in Africa. The responsible authorities or bodies have neglected this defect too. The effects of the malformation are related to substantial mortality, disability and psychological costs (the psychosocial problem of having an infant with a 'monstrous outlook' or 'two heads'). Although encephalocele is a rare congenital anomaly, it is correlated with severe morbidity and mortality if untreated. ${ }^{78}$ Folic acid supplementation and termination of pregnancies diagnosed with encephalocele prenatally have reduced the occurrence or incidence of this type of congenital abnormality, particularly in developed (high-income) countries.

The birth prevalence of encephalocele was $0.02 \%$ (or 2 per 10000 births) in this meta-analysis. This finding is comparable to different findings reported elsewhere (ranged from 0.8 to 4.0 per 10000 births). ${ }^{4-8} 11$ Besides, it is comparable to the review done in low-income and middle-income countries (2.1 per 10000 births) ${ }^{50}$ The review result suggested that low-income and middleincome countries were mostly affected by this malformation every year. ${ }^{50}$ However, the review did not include studies from Africa except for two studies. Our finding

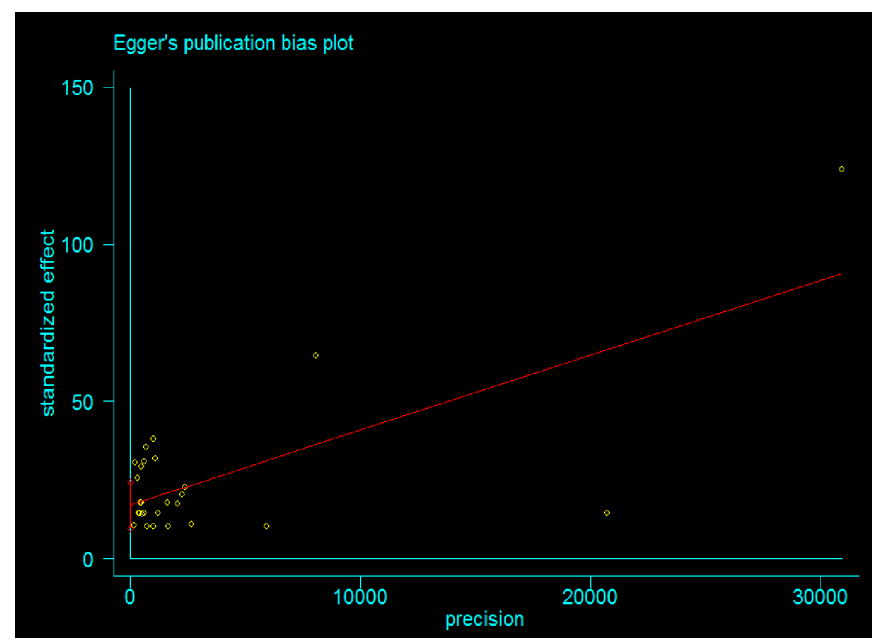

Figure 7 Egger's publication bias plot. 
is higher than that reported by certain high-income countries (1.0 per 10000 births). ${ }^{1}$ Recent research shows that the prevalence of encephalocele varies across time, geography and population to population. ${ }^{8}$ Our analysis also revealed considerable differences between African countries and prevalence over time. Subgroup analyses were carried out based on the study nation, design, birth outcome, birth status and the availability of a folic acid fortification programme. As a result, a considerable disparity in the occurrence of encephalocele in different African countries was discovered in this study. Nigeria $0.06 \%$, Sudan $0.04 \%$, Egypt $0.04 \%$, Congo (DR) $0.02 \%$, Ethiopia $0.02 \%$ and Tanzania $0.02 \%$ had a high prevalence of encephalocele. This disparity could be explained by mothers' levels of knowledge about folic acid supplementation, as well as the country's health policy on folic acid fortification and other preventive measures. The notion of the presence of geographical variation between the countries was supported by the previous studies. ${ }^{6-8}$ The variation in different publication years of the different studies was noted using time trend analysis. The highest peak of encephalocele in prevalence was seen in 1992, 2007, 2014-2015 and 2005. The prevalence estimate for live births was similar to both live birth and stillbirth estimations. Surprisingly, all studies in this review were facility-based studies. Thus, there may have been an underestimating of encephalocele estimations because it did not include many stillbirths and home deliveries in the community context (included the participants delivered at the hospital setting).

The findings of the current systematic review and metaanalyses should be interpreted based on some limitations. The presence of significant variation across countries may affect/underestimate the pooled prevalence of the defect in Africa. Moreover, the prevalence estimate did not include terminated pregnancies of encephalocele; this may lower the pooled prevalence estimates. The estimated report may be influenced by the sample size's adequacy or variability. Furthermore, publication bias was detected by Egger's regression tests that may not decrease by trim and fill meta-analyses. Underestimation of the burden of encephalocele should be considered because many home births that are delivered in the community setting were not included. The review was represented by 27 studies due to limited available data about encephalocele.

Fragmented studies have been conducted to estimate the country-level prevalence of encephalocele. However, the findings were inconsistent and varied and there is no empirical evidence on the pooled prevalence estimates in Africa. Besides, studies on isolated encephaloceles are quite rare. The available evidence on encephalocele is in aggregate/combined form with either neural tube defects or birth defects of the central nervous system. Interestingly, the present systematic review and metaanalysis highlight the birth prevalence of encephalocele in African countries, providing crucial evidence for policy-makers, clinicians and the concerned bodies who neglected the burden of this defect. Recognising a high burden in Africa may initiate the policymakers to develop effective control and prevention strategies and may use their ultimate potential in reducing the burden of the encephalocele and making further research possible. Additionally, the high burden detected in our review may inform policymakers positively on policy decisions related to prevention efforts in Africa where policymakers may feel that this is not a big enough problem for prioritising prevention funds. The severity, the observed differences in prevalence estimate among countries, may contribute by informing clinical and policy guidelines in the prioritisation of interventions and maintaining robust surveillance systems that track or screen all pregnancy outcomes or all births in Africa. Besides, future research works might benefit from the information gained from the current review when designing and developing new studies. Furthermore, it helps additional clinical studies to focus on risk factors, prevention, intervention and psychosocial outcomes of the defect in isolated form. More research should be conducted in Africa to assess the effectiveness of folic acid in reducing the burden of the encephalocele and, notably, to determine how and why interventions either work or do not work in each country that followed either a mandatory or voluntary fortification policy. All these should be the ultimate contribution of this review to the field in assisting the prevention and control programmes.

\section{CONCLUSION}

This systematic review and meta-analysis showed that encephalocele is highly prevalent in Africa. The prevalence of encephalocele was high in Nigeria, Sudan, Egypt, DR of Congo, Ethiopia and Tanzania. A similar prevalence of encephalocele was observed in the studies that included only live births and in studies that included both live births and stillbirths. The reviewers recommend that special awareness be created for reproductive-age women with an emphasis on prevention in order to reduce the encephalocele burden. Due to the scarcity of data on encephalocele in Africa, more primary research is needed to increase the estimated burden of the encephalocele and promote favourable aid strategies for prevention.

Contributors $\mathrm{MO}$ and $\mathrm{AD}$ participated in the conceptualisation of the review protocol, formal analysis, methodology or study design, writing-original draft, interpretation, writing-review and editing, and approving the final draft. M0 and AD: quality assessment, data extraction, and literature review. All authors read and approved the manuscript. MO act as the guarantor of the study.

Funding The authors have not declared a specific grant for this research from any funding agency in the public, commercial or not-for-profit sectors.

Competing interests None declared.

Patient consent for publication Not applicable.

Provenance and peer review Not commissioned; externally peer reviewed.

Data availability statement Data are available on reasonable request. All data relevant to the study are included in the article or uploaded as online supplemental information. All relevant data are available within the manuscript. The data 
sets used and/or analysed during the current review are available from the corresponding author on reasonable request.

Supplemental material This content has been supplied by the author(s). It has not been vetted by BMJ Publishing Group Limited (BMJ) and may not have been peer-reviewed. Any opinions or recommendations discussed are solely those of the author(s) and are not endorsed by BMJ. BMJ disclaims all liability and responsibility arising from any reliance placed on the content. Where the content includes any translated material, BMJ does not warrant the accuracy and reliability of the translations (including but not limited to local regulations, clinical guidelines, terminology, drug names and drug dosages), and is not responsible for any error and/or omissions arising from translation and adaptation or otherwise.

Open access This is an open access article distributed in accordance with the Creative Commons Attribution Non Commercial (CC BY-NC 4.0) license, which permits others to distribute, remix, adapt, build upon this work non-commercially, and license their derivative works on different terms, provided the original work is properly cited, appropriate credit is given, any changes made indicated, and the use is non-commercial. See: http://creativecommons.org/licenses/by-nc/4.0/.

ORCID iD

Mohammed Oumer http://orcid.org/0000-0003-4289-8712

\section{REFERENCES}

1 The Centers for Disease Control and Prevention (CDC). Birth defects, specific birth defects, neural tube defects, facts about encephalocele. Available: https: // www.cdc.gov/ncbddd/ birthdefects/encephalocele.html

2 Rare disease databases: birth defect. Available: https://rarediseases. org/rare-diseases/encephalocele/

3 Mai CT, Isenburg JL, Canfield MA, et al. National population-based estimates for major birth defects, 2010-2014. Birth Defects Res 2019;111:1420-35.

4 Moore KL, Persaud TVN. Chapter: Congenital anomalies of the brain and spinal cord Saunders. In: The developing human. clinically oriented embryology. 8th edition.

5 Sadler TW. Chapter: Clinical correlates in central nervous system Embryology. In: Langman's Medical Embryology. 11th Edition.

6 Sadler TW. Langman's Medical EmbryologyChapter: clinical correlates in central nervous system embryology. 12th Edition. Wolters Kluwer: Lippincotte Williams and Wilkins, 2011.

7 Bot GM, Ismail NJ, Mahmud MR, et al. Giant encephalocele in Sokoto, Nigeria: a 5-year review of operated cases. World Neurosurg 2020;139:51-6.

8 Munyi N, Poenaru D, Bransford R, et al. Encephalocele--a single institution African experience. East Afr Med J 2009;86:51-4.

9 Jeffrey M, Rosenfeld V, Watters DAK. Neurosurgery in the tropics: a practical approach to common problems. Macmillan Education Ltd 2000.

10 Rowland CA, Correa A, Cragan JD, et al. Are encephaloceles neural tube defects? Pediatrics 2006;118:916-23.

11 Suwanwela C, Suwanwela N. A morphological classification of sincipital encephalomeningoceles. J Neurosurg 1972;36:201-11.

12 Rolo A, Galea GL, Savery D, et al. Novel mouse model of encephalocele: post-neurulation origin and relationship to open neural tube defects. Dis Model Mech 2019;22:dmm040683.

13 Berry RJ, Li Z, Erickson JD, et al. Prevention of neural-tube defects with folic acid in China. N Engl J Med Overseas Ed 1999;341:1485-90.

14 Czeizel AE, Dudás I. Prevention of the first occurrence of neural-tube defects by periconceptional vitamin supplementation. N Engl J Med 1992;327:1832-5

15 Moher D, Liberati A, Tetzlaff J, et al. Preferred reporting items for systematic reviews and meta-analyses: the PRISMA statement. PLoS Med 2009;6:e1000097.

16 Moola S, Munn Z, Tufanaru C. Chapter 7: Systematic reviews of etiology and risk. In: Aromataris E, Munn Z, eds. Joanna Briggs Institute Reviewer's Manual. The Joanna Briggs Institute, 2017. https://reviewersmanualjoannabriggsorg/

17 Endalamaw A, Engeda EH, Ekubagewargies DT, et al. Low birth weight and its associated factors in Ethiopia: a systematic review and meta-analysis. Ital J Pediatr 2018;44:141.

18 Higgins JPT, Thompson SG, Deeks JJ, et al. Measuring inconsistency in meta-analyses. BMJ 2003;327:557-60.

19 Munn Z, Moola S, Lisy K, et al. Methodological guidance for systematic reviews of observational epidemiological studies reporting prevalence and cumulative incidence data. Int J Evid Based Healthc 2015;13:147-53.
20 Borenstein M, Hedges LV, Higgins JPT, et al. A basic introduction to fixed-effect and random-effects models for meta-analysis. Res Synth Methods 2010;1:97-111.

21 Egger M, Smith GD, Schneider M, et al. Bias in meta-analysis detected by a simple, graphical test. BMJ 1997;315:629-34.

22 Begg CB, Mazumdar M. Operating characteristics of a RANK correlation test for publication bias. Biometrics 1994:50:1088-101.

23 Airede KI. Neural tube defects in the middle belt of Nigeria. J Trop Pediatr 1992;38:27-30.

24 Adetiloye VA, Dare FO, Oyelami OA. A ten-year review of encephalocele in a teaching hospital. International Journal of Gynecology \& Obstetrics 1993;41:241-9.

25 Mukhtar-Yola M, Ibrahim M, Belonwu R. The prevalence and perinatal outcome of obvious congenital malformations among inborn babies at Aminu Kano teaching Hospital, Kano. Nigerian Journal of Paediatrics 2005;32:47-51.

26 Ugwu RO, Eneh AU, Oruamabo RS. Neural tube defects in a university teaching hospital in southern Nigeria: trends and outcome. Niger J Med 2007;16:368-71.

27 Anyanwu L-J, Danborno B, Hamman W. The prevalence of neural tube defects in live born neonates in Kano, north-western Nigeria. Sub-Saharan Afr J Med 2015;2:105-9.

28 Nnadi D, Singh S. The prevalence of neural tube defects in northwest Nigeria. Saudi J Health Sci 2016;5:6-10.

29 Abbey M, Oloyede O, Bassey G, et al. Prevalence and pattern of birth defects in a tertiary health facility in the niger delta area of Nigeria. International Journal of Women's Health 2017;9:115-21.

30 Ekwochi U, Asinobi IN, Osuorah DCl, et al. Pattern of congenital anomalies in newborn: a 4-year surveillance of newborns delivered in a tertiary healthcare facility in the south-east Nigeria. $J$ Trop Pediatr 2018:64:304-11.

31 Buccimazza SS, Molteno CD, Dunne TT, et al. Prevalence of neural tube defects in Cape town, South Africa. Teratology 1994;50:194-9.

32 Delport SD, Christianson AL, van den Berg HJ, et al. Congenital anomalies in black South African liveborn neonates at an urban academic Hospital. S Afr Med J 1995;85:11-15.

33 Venter PA, Christianson AL, Hutamo CM, et al. Congenital anomalies in rural black South African neonates--a silent epidemic? S Afr Med $J$ 1995;85:15-20

34 Kinasha AD, Manji KP. The incidence and pattern of neural tube defects in Dar ES Salaam, Tanzania. European Journal of Pediatric Surgery Supplement 2003:S38-9.

35 Kishimba RS, Mpembeni R, Mghamba JM, et al. Birth prevalence of selected external structural birth defects at four hospitals in Dar ES Salaam, Tanzania, 2011-2012. J Glob Health 2015;5:020411.

36 Muga R, Mumah SCJ, Juma PA. Congenital malformations among newborns in Kenya. African Journal of Food, Agriculture, Nutrition and Development 2009;9.

37 Agot GN, Mweu MM, Wang'ombe JK. Prevalence of major externa structural birth defects in Kiambu County, Kenya, 2014-2018. Pan African Medical Journal 2020;37.

38 Elsheikh GEA, Ibrahim SA. Neural tube defects in Omdurman maternity Hospital, Sudan. Khatoum Medical Journal 2009;2:185-90.

39 Omer IM, Abdullah OM, Mohammed IN, et al. Research: prevalence of neural tube defects Khartoum, Sudan August 2014-July 2015. BMC Res Notes 2016;9:495.

40 Gedefaw A, Teklu S, Tadesse BT. Magnitude of neural tube defects and associated risk factors at three teaching hospitals in Addis Ababa, Ethiopia. Biomed Res Int 2018;2018:4829023.

41 Abebe S, Gebru G, Amenu D. Prevalence and patterns of birth defects among newborns in southwestern Ethiopia: retrospective study 2020

42 Ahuka OL, Toko RM, Omanga FU, et al. Congenital malformations in the north-eastern Democratic Republic of Congo during civil war. East Afr Med J 2006;83:95-9.

43 Houcher B, Bourouba R, Djabi F, et al. The prevalence of neural tube defects in Sétif university maternity Hospital, Algeria-3 years review (2004-2006). Pteridines 2008;19:12-18.

44 Njamnshi AK, Djientcheu VdeP, Lekoubou A, et al. Neural tube defects are rare among black Americans but not in sub-Saharan black Africans: the case of Yaounde - Cameroon. J Neurol Sci 2008;270:13-17.

45 Mohammed YA, Shawky RM, Soliman AAS, et al. Chromosomal study in newborn infants with congenital anomalies in Assiut university hospital: cross-sectional study. Egyptian Journal of Medical Human Genetics 2011;12:79-90.

46 Nasri K, Ben Fradj MK, Hamdi T, et al. Epidemiology of neural tube defect subtypes in Tunisia, 1991-2011. Pathol Res Pract 2014:210:944-52. 
47 Radouani MA, Chahid N, Benmiloud L, et al. Prevalence of neural tube defects: Moroccan study 2008-2011. Open Journal of Pediatrics 2015;05:248-55.

48 Alhassan A, Adam A, Nangkuu D. Prevalence of neural tube defect and hydrocephalus in northern Ghana. Journal of Medical and Biomedical Sciences 2017;6:18-23.
49 El-Moghrabi HA, Ziuo FYM, El- houni NE. Congenital malformations and its relation with consanguineous marriages at Benghazi Libya. Int J Stem Cell Regen Med 2019;1:105.

50 Annie L, Dora P, Simrita S. Estimating the burden of neural tube defects in low- and middle-income countries. Journal of Global health 2014;4. 